\title{
Trophic interactions of reef-associated predatory fishes (Hexagrammos otakii and Sebastes schlegelii) in natural and artificial reefs along the coast of North Yellow Sea, China
}

\author{
Rongliang Zhang a,b,d, Hui Liu ${ }^{\text {a,c }}$, Qianqian Zhang ${ }^{\text {a,c }}$, Hua Zhang ${ }^{\text {b }}$, Jianmin Zhao ${ }^{\text {a,c,* }}$

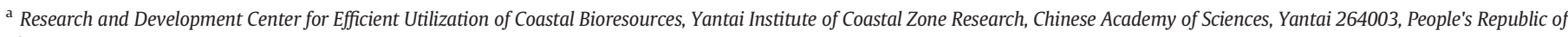 \\ China

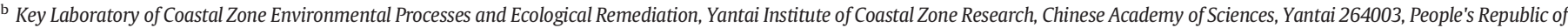 \\ China \\ ${ }^{c}$ Muping Coastal Environment Research Station, Yantai Institute of Coastal Zone Research, Chinese Academy of Sciences, Yantai 264003, People's Republic of China \\ d University of Chinese Academy of Sciences, Beijing 100049, People's Republic of China
}

\section{H I G H L I G H T S}

- Biomass of H. otakii and S. schlegelii were comparable or higher at artificial reefs.

- Prey assemblages perhaps varied between the artificial reef and the natural reef.

- Both niche width and niche overlap were smaller at artificial reefs.

- Artificial reefs could supply reef predatory fish with high habitat quality.

\section{A R T I C L E I N F O}

\section{Article history:}

Received 1 April 2021

Received in revised form 31 May 2021

Accepted 1 June 2021

Available online $\mathrm{xxxx}$

Editor: Damia Barcelo

\section{Keywords:}

Reef habitat

Prey availability

Trophic niche

Habitat quality
GRAPH ICA L A B STRACT

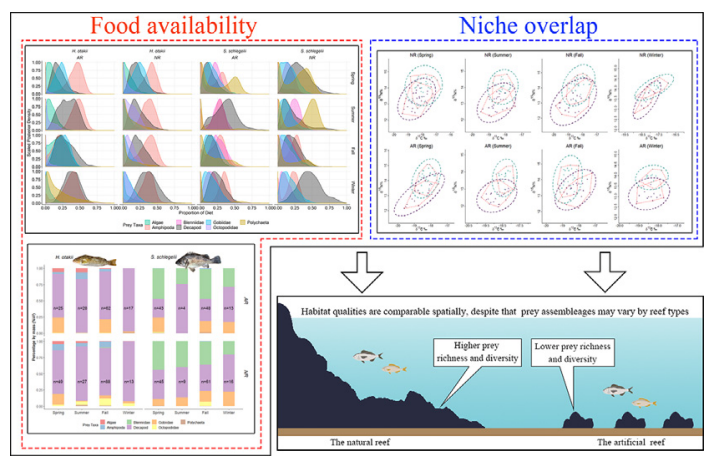

\begin{abstract}
A B S T R A C T
Large reef-associated predatory fishes play important roles in aquatic ecosystem along coast because of their ecological functions and economic values to recreational and commercial fisheries. This study was carried out to assess the function of artificial reefs as alternative habitats for two common reef-associated predatory fishes in the north of Yellow Sea, China, Fat Greenling Hexagrammos otakii and Korean rockfish Sebastes schlegelii. According to the catch per unit effort (CPUE), the biomass of predatory fishes at the artificial reef was comparable ( $\mathrm{H}$. otakii) to or higher (S. schlegelii) than the natural reef, highlighting the environmental fitness of the artificial reef. Gut content analysis (GCA) showed that $H$. otakii preyed primarily on Decapod and Amphipoda, while S. schlegelii exhibited higher dependence on fish (Blinniidae and Gobiidae) and Decapod. Collectively, prey richness and diversity were greater at the natural reef relative to the artificial reef, and prey availability may be different between the two reef types. Stable isotopic analysis (SIA) in conjunction with the Bayesian mixing model (MixSIAR) revealed spatial and interspecific difference on the diet composition of H. otakii and S. schlegelii as well. Based on GCA and MixSIAR result, the habitat-specific effect on the prey availability was confirmed. Additionally, comparisons on trophic niche breadth and niche overlap indicated higher trophic diversity but relatively lower food resources partitioning degree for both species at the natural reef than at the artificial reef. Our results suggest that artificial reefs may harbor a different prey assemblage comparing to natural reef but can support large populations of predatory reef-associated fishes and accommodate their coexistence.
\end{abstract}

(c) 2021 Elsevier B.V. All rights reserved.

\footnotetext{
* Corresponding author at: Research and Development Center for Efficient Utilization of Coastal Bioresources, Yantai Institute of Coastal Zone Research, Chinese Academy of Sciences, Yantai 264003, People's Republic of China.

E-mail address: jmzhao@yic.ac.cn (J. Zhao).
} 


\section{Introduction}

As an important element in the restoration of the degraded coastal marine habitats, artificial reefs have been established globally to mimic the ecological functions of natural reefs (Baine, 2001; Carr and Hixon, 1997; Layman and Allgeier, 2020). It was reported that artificial reefs had a great effect on the diet of reef-associated fish species, especially on the upper trophic level species with great commercial and ecological values (Cresson et al., 2019; Lowry et al., 2014). Usually, large predatory fishes can exert top-down effects in regulating population with lower trophic levels and structuring local community by consumption directly or being an predator risk indirectly, and their feeding strategies will influence on the distribution of resource and transmission of energy through the ecosystems resources and transmission of energy through the ecosystems (Heithaus et al., 2013; Terborgh and Estes, 2010; Williams et al., 2004). Thus knowledge of the trophic ecology of these reef-associated predators is important in understanding and evaluating the function of artificial reefs in the maintenance of fish populations.

Over the past decades, many studies have been conducted on the trophic ecology of reef habitat-specific fishes in artificial reefs, with most have carried in Gulf of Mexico (Brewton et al., 2020; Schwartzkopf et al., 2017; Simonsen et al., 2015; Tarnecki and Patterson, 2015; Wells et al., 2008). Relevant studies performed rigorous comparison on the feeding ecology of reef-associated fishes (e.g. red snapper Lutjanus. campechanus) and highlighted the effect of the habitat structures, seasons and ontogeny on the feeding strategies. However, most of these studies have been conducted at reefs formed by oil platforms, while very few have concerned the reefs designed for fishery enhancement or habitat restoration. Moreover, the previous studies mainly focused on the diet variation of one single fish species, which overlooked the trophic interactions among species with similar trophic levels. The potential trophic overlap or divergence among upper trophic level fishes commonly determines the degree of trophic redundancy or complementary, which are important for the community stability (Bascompte et al., 2005; Heithaus et al., 2013; Kondoh, 2008). At present, there is a lack of studies regarding to the trophic interactions among the reef dwelling predatory fishes living in artificial reefs, including the direct (e.g., predator-prey) and indirect (e.g., competition for a shared resource) interactions.

The Fat Greenling Hexagrammos otakii and Korean rockfish Sebastes schlegelii are two common upper level predatory fish species in Yellow Sea of China, both usually spend the major life history amid reefassociated water (Kwak et al., 2005; Kang and Shin, 2006; Zhang et al., 2015). They used to serve a prominent role in supporting local nearshore fishery in terms of their abundance and commercial values. In past decades, loss and degradation of the original coastal environments have threatened the populations of these two species, as a result of a variety of human activities (e.g. coastal development, overfishing and pollution). Development of artificial reefs has been increasingly carried out in the Yellow Sea coast as one of the major restoration approaches to support the fish living. Although the feeding ecology of both $\mathrm{H}$. otakii and S. schlegelii in artificial reefs in Yellow sea, China have been reported in a few previous researches (Wu et al., 2018; Zhang et al., 2018). Trophic interaction between the two species with similar trophic level has yet been addressed. Moreover, how the feeding strategy and trophic interaction of/between these two predatory fishes vary from artificial to natural reefs have not explored. As artificial reefs are alway constructed to supplement or enhance natural rocky areas, a comparative study between artificial reefs and relatively undisturbed natural reefs are not doubt imperative and necessary, to provide more robust and informative evidence for the function of artificial reefs in supporting predatory fishes living and accommodating their coexistence.

In this study, we studied the trophic ecology of S. schlegelii and $H$. otakii and their potential niche partitioning at both the artificial reef and natural reefs of Yellow Sea coast, based on Gut content analysis
(GCA) and stable isotopic analysis (SIA). We present two questions: 1) Are the feeding strategy of both two species different between the artificial reef and the natural reef 2 ) Are the trophic overlap between S. schlegelii and $H$. otakii at the artificial reef comparable to those at the natural reef. Via the two questions, we sought to compare the habitat quality of the artificial reefs relative to their natural counterparts in supporting these two reef-associated predators, and give an interpretation to their coexistence in reef habitat. This information is expected to provide insights into the ecological role of artificial reefs and guide the optimization of their deployment and management in the future.

\section{Material and methods}

\subsection{Study area and sampling collection}

This study was conducted in south coast of Northern Yellow Sea, China, with approximately $18 \mathrm{~km}$ distance between the natural reef and the artificial reef (Fig. 1). The artificial reef has been established over seven years (started from 2009 to 2013), with material mainly composed of quarry rocks and concrete cubes $3 \mathrm{~m} \times 3 \mathrm{~m} \times 3 \mathrm{~m}$. The depth at both artificial reef and natural reef ranges from 10 to $20 \mathrm{~m}$. At each site, six sampling stations were evenly installed. At each station, 10 fishing traps connected with each other (defined as one gear unit) were used to collect predatory fish samples. Our sampling was carried out in May 2018, August 2018, November 2018, and February 2019, representing spring, summer, fall, and winter seasons, respectively. Benthic fish and macro-invertebrates were collected using fishing traps placed at sea bottom for $48 \mathrm{~h}$, and small benthos were sampled from oyster bags placed a few days in advance. Once brought on boat, all biota samples were stored in the refrigerator until they were transported to the laboratory. Then all samples were identified to species level for fish and at least genus level for macrobenthos. Fish were measured standard length (SL) in mm and weighted (wet weighted in g) prior to being labeled for subsequent GCA and stable isotopes determination. For fish, dorsal white muscle and gut were dissected, and the latter was preserved with 70\% ethanol for subsequent analysis. For benthos, only abdomen muscle if possible or the whole body was used for stable isotopic analysis.

\subsection{Community structure analysis}

To estimate the relative biomass of each species, fishery yields at each station was calculated as Catch-per-unit-effort (CPUE) (Calkins, 1961), which is defined as:

$\mathrm{CPUE}=\frac{\sum C i}{\sum f i}$

where $C_{i}$ is the catch (expressed in wet weight) of species $i, f_{i}$ is its fishing efforts, and $i$ represents $H$. otakii or $S$. schlegelii here. In the current study, one unit of effort was defined as one gear unit in one day and night, and CPUE was denoted by $\mathrm{g} \cdot \mathrm{unit}^{-1} \cdot \mathrm{d}^{-1}$.

\subsection{Gut content analysis (GCA)}

Following the fixation, prey items in gut contents were identified to the lowest possible taxon by using a stereoscopic microscope, and their wet weight was measured up to $0.01 \mathrm{~g}$. Otoliths, large pincers, and other hard structures were considered when present to help identify heavily degraded prey items. A vacuity coefficient (\%VC) was calculated as the percentage of stomach with preys account for total stomachs. To examine the relative importance of different prey taxa, frequency of occurrence (\%FO), percentage by number $(\% \mathrm{~N})$, percent weight $(\% \mathrm{~W})$ were calculated, then index of relative importance (IRI) and corresponding \%IRI was calculated. 


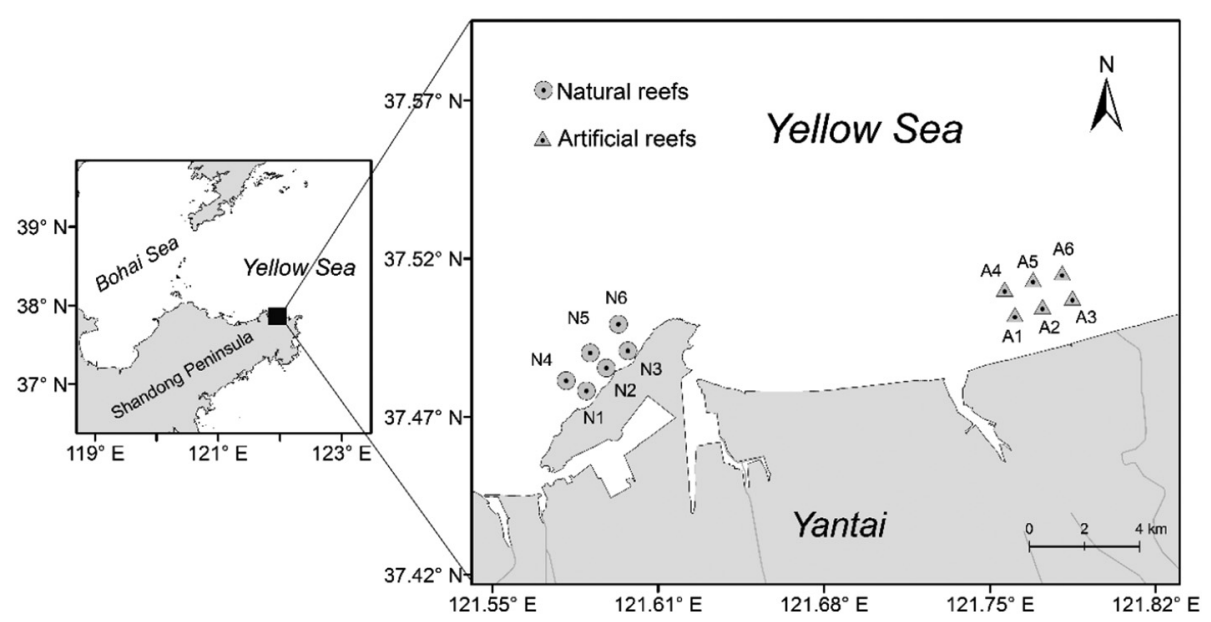

Fig. 1. Location of study sites in the south coast of North Yellow Sea, China, showing two habitat types including natural reefs (N1 to N6) and artificial reefs (A1 to A6).

To minimize the influence of dominate food items, the \%W data of all identifiable preys was square root transformed to build a BrayCurtis resemblance matrix, Shannon-Wiener Diversity Index $\left(H^{\prime}\right)$ based on scaled prey \%W was used to reflect the forging diversity of each species. Moreover, permutation multivariate analysis of variance (PERMANOVA) using 99,999 permutations and subsequent pairwise comparisons were then employed to examine whether season, species, season $\times$ species interaction would impact on the stomach contents (measured by \%W). Subsequently, similarity percentages (SIMPER) tests were undertaken to further explore prey items most accounting for driving any dissimilarities observed as a function of species and seasons. All statistical analysis of GCA was finished in R using “vegan” packages (Oksanen et al., 2020).

\subsection{Stable isotopes analysis (SIA)}

Prior to stable isotopes determination, all muscle samples were freeze-dried for at least $48 \mathrm{~h}$ and ground to a fine and homogeneous powder using a mortar and pestle, then both $1 \mathrm{M} \mathrm{HCl}$ and 2:1 mixture of chloroform and methanol were used to minimize the difference of $\delta^{13} \mathrm{C}$ values caused by inorganic carbonates and lipid content. No such treatment was necessary in $\delta^{15} \mathrm{~N}$ measurement. SIA was carried out using a mass spectrometer (Delta V Advantage, Thermo Fisher Scientific, US) connected to an elementary analyzer (Flash EA 1112, Thermo Fisher Scientific, US) via an interface (Conflo III, Thermo Fisher Scientific, US). The stable isotopic ratios were denoted as $\delta$ notation, as the following equation:

$\delta \mathrm{X}=\left[\frac{\mathrm{R}_{\text {sample }}}{\mathrm{R}_{\text {standard }}}-1\right] \times 10^{3}$

where $\mathrm{X}$ means ${ }^{13} \mathrm{C}$ or ${ }^{15} \mathrm{~N}$ and R represents ${ }^{13} \mathrm{C} /{ }^{12} \mathrm{C}$ or ${ }^{15} \mathrm{~N} /{ }^{14} \mathrm{~N}$. $\mathrm{R}_{\text {sample }}$ was measured for biota samples and $\mathrm{R}_{\text {standard }}$ is an international standard (Vienna Pee Dee belemnite limestone carbonate for carbon and atmospheric air for nitrogen). For both $\delta^{13} \mathrm{C}$ and $\delta^{15} \mathrm{~N}$, measurement precision was within $0.2 \%$. Additionally, to examine whether ontogenetic shift had impact on forging habit, simple linear regressions were conducted to determine the relationship between SL and each of carbon and nitrogen stable isotope value, respectively.

Apart from S. schlegelii and H. otakii, SIA was limited to include species taxonomically similar to prey items presented in gut samples, to make the assessment of food contribution more reliable. Food items which were not captured from traps and oyster bags were collected from the guts of each species of scorpionfish. Multiple analysis of variance (MANOVA) based on stable isotopes signatures was executed to access the variation of dependent variables $\left(\delta^{13} \mathrm{C}\right.$ and $\left.\delta^{15} \mathrm{~N}\right)$ within factors (species and seasons). Significant dependent variables identified from MANOVA were followed with univariate analysis of variance (ANOVA) or Kruskal-Wallis tests, depending on whether the requirements of variance homogeneity coupled with normality were fulfilled, on a given factor to examine which level leads to the difference. Afterwards, the pairwise test was applied to distinguish the source of significance within significant factors. The ANOVA or Kruskal-Wallis test, in combination with post hoc tests, were also applied to investigate the interspecific or spatial difference of CPUE, prey diversity $\left(H^{\prime}\right)$ and other parameters present in this study. Statistical analyses were performed in $\mathrm{R}$ using the "multcomp" and "pgirmess" package (Hothorn et al., 2008).

\subsection{Bayesian mixing models}

Bayesian mixing models were adopted to estimate the contribution of a potential prey resource to the diet of each species using Bayesian Mixing Models in R (MixSIAR) (Stock and Semmens, 2016). The MixSIAR model allows for uncertainties associated with isotopic signatures and diet-to-tissue discrimination factors (Parnell et al., 2010; Parnell et al., 2013; Phillips et al., 2014), which were set $1 \pm 0.1 \%$ and $3.4 \pm 0.11 \%$ or for ${ }^{13} \mathrm{C}$ and ${ }^{15} \mathrm{~N}$ respectively as recommended in Post (2002). Food items used in the model was derived from GCA, as well as a prior knowledge about their feeding preferences (Kwak et al., 2005; Zhang et al., 2014, 2018; Wu et al., 2018).

In order to obtain more constrained and logically interpretable results, prey items with similar taxonomic status were grouped as a potential source, and mean \pm SD of their $\delta^{13} \mathrm{C}$ and $\delta^{15} \mathrm{~N}$ values was calculated. Final groups of sources used as input for the mixing models were seven categories in total, namely algae, Decapod, Gobiidae, Blenniidae, Amphipoda, polychaetes, and Octopodidae. Since no significant spatial difference on stable isotope values of specific sources was detected, sources from the natural reef and the artificial reef were treat as common ones. It's important to note that some prey species were not identified based on GCA, hence all suspect preys collected from external environment and with similar morphological characteristics were treated as members within a specific group. For instance, assume a prey item in gut content was identified as a member of Gobiidae but unrecognized to species level, taxonomically similar individuals (e.g., Chaeturichthys stigmatias or Tridentiger trigonocephalus) sampled by fishing gears would be included in the Gobiidae group.

Mixing models were performed with 300,000 iterations (200,000 burns-in), with informative priors from \%W of each source group based on the GCA were specified. To examine whether the model run correctly, Gelman-Rubin, Heidelberger-Welch and Geweke tests were used in examining the convergence in the model (Stock and Semmens, 2016). 
The trophic niche breadth was measured by corrected Standard Ellipse Area (SEAc), which was estimated as a quantification of the isotopic $\delta$-space, to avoid bias owing to small sample sizes (Jackson et al., 2011). Potential isotopic niche overlap between species was also quantified as a percentage of shared SEAc (niche overlap ratio, \%OA). It was considered significant when \%OA greater or equal to 0.6 , representing a heavy diet overlap between two specific populations (Dance et al., 2018; Guzzo et al., 2013; Schoener, 1968). All calculations of trophic niche metrics were completed using the Stable Isotope Analysis in $\mathrm{R}$ with "SIAR" package (Parnell and Jackson, 2013) and Stable Isotope Bayesian Ellipses in R with "SIBER" package (Jackson et al., 2011). All statistical analyses significant at $\alpha=0.05$ were further tested with appropriate post hoc tests.

\section{Results}

\subsection{Fishery yields}

Seasonal fluctuation of CPUE for both species at two habitat types was exhibited in Table 1. Overall, S. schlegelii has higher CPUE than $H$. otakii in both natural reef $(231.4 \pm 153.7$ vs. $205.9 \pm 135.9$ $\mathrm{g} \cdot$ unit $\left.^{-1} \cdot \mathrm{d}^{-1}\right)$ and artificial reef $(367.4 \pm 281.7$ vs. $166 \pm 186.5$ $\mathrm{g} \cdot$ unit $^{-1} \cdot \mathrm{d}^{-1}$ ) (Kruskal-Wallis test, $\left.p<0.05\right)$. The CPUE estimate of $S$. schlegelii was higher at the artificial reef than at the natural reef, whereas there is no significant difference for $H$. otakii between the two reef habitats.

\subsection{GCA results}

During all sampling periods, a total of $410 \mathrm{H}$. otakii ( 184 and 226 for the artificial and natural reefs) and 430 S. schlegelii (200 and 230 for the artificial and natural reefs) were collected. The standard length (SL) of $H$. otakii ranged from $8.6-20.0 \mathrm{~cm}$ at the artificial reef and $8.2-26.4 \mathrm{~cm}$ at the natural reef, respectively; SL of $S$. schlegelii ranged from $7.3-30$ at the artificial reef and $9.6-35.3 \mathrm{~cm}$ at the natural reef, respectively. Information of stomach number with identifiable prey items and \%VC for both H. otakii and S. schlegelii is displayed in Table 1. Overall, S. schlegelii displayed higher \%VC than $H$. otakii, as well as higher vacuity values obtained at the artificial reef for both species.

The summaries consist of \%W and \%IRI of each prey items in gut content were depicted in Table S1 and \%W of each prey categories in Fig. 2. Of totally $309 \mathrm{H}$. otakii informative stomachs, at least 28 prey species (22 and 26 for the artificial and natural reefs, with 20 in common) were discerned, which were categorized into seven taxonomic groups: Decapod, Amphipoda, Polychaeta, Octopodidae, algae, Gobiidae, Blenniidae. Of the 239 S. schlegelii informative stomachs, at least 21 species (16 and 20 for the artificial and natural reefs, with 15 in common) were detected, with similar taxonomic composition (except algae) as H. otakii. Generally, Amphipoda and Decapod were two predominate prey categories for $\mathrm{H}$. otakii at both sites. Compared to those living at natural reefs, $H$. otakii at the natural reef consumed more Amphipoda (\%W: $7.79 \%$ vs. $3.18 \%$, \%IRI: $63.38 \%$ vs. $40.75 \%$ ) and less Decapod (\%W: $80.53 \%$ vs. $74.37 \%$ and \%IRI: $51.96 \%$ vs. $29.06 \%)$. In contrast, S. schlegelii fed primarily on Decapod at both the artificial and the natural reef (\% W: $46.84 \%$ vs. $46.25 \%$, IRI: $42.25 \%$ vs. $44.3 \%$ ) and fish, which is constituted of Blennidae (\%W: $35.73 \%$ vs. $33.95 \%$, IRI: $35.59 \%$ vs. $34.84 \%$ ) and Gobiidae (\%W: $16.32 \%$ vs. $16.52 \%$, IRI: $15.93 \%$ vs. $17.71 \%$ ). According to the Shannon-Wiener Diversity Index $\left(H^{\prime}\right)$ calculations result (Table 1), higher diversity of prey compositions was found in specimens dwelling at the natural reef than those at the artificial reef for both species (seasonal averaging $H^{\prime}: 2.07$ vs. 1.85 for $H$. otakii, 1.91 vs. 1.76 for S. schlegelii).

Based on the PERMANOVA ( $p<0.05$ ), spatial differences of the $H$. otakii stomach compositions were detected in all seasons except winter, though magnitudes of the difference were relatively low in all cases $(R<0.1)$. Specifically, the prey Palaemon ortmanni in spring (SIMPER, \% dissimilarity contribution, hereafter as dif con $=17.8 \%$ ), Alpheus distinguendus in summer (dif con $=20.07 \%)$, P. ortmanni $($ dif con $=$ $16.50 \%$ ) and Caprellidae sp. ( dif con $=14.89 \%$ ) in fall were the typifying species driving the regional differences. In contrast, spatial difference of the S. schlegelii gut content were not observed in any season, where Gobiidae and Enedrias fangi made up similar proportion of the prey composition all year round at both reef types.

Significant interspecific differences of the gut content were observed in fish organisms living at both reef in all seasons except fall (PERMANOVA, $p<0.05$ for all cases), albeit with magnitudes at a relatively low level ( $R<0.2$ for all cases). Based on the subsequent SIMPER, the disparities at the natural reef were mainly as a result of that Decapod (mean dif con $=23.17 \%$ ) played a principal role in the diet of $H$. otakii, while Blenniidae (mean dif con $=11.17 \%$ ) and Gobiidae (mean dif con $=10.83 \%$ ) contributions were greater to S. schlegelii than to $H$. otakii. The pattern of interspecific difference at the artificial reef was consistent with that at the natural reef except in fall, with same divergent categories as well, and the mean dif cons were $19.45 \%$ for Decapod, $9.82 \%$ for Gobiidae and $11.72 \%$ for Blenniidae, respectively.

\subsection{Isotopic signatures}

Totally 184 H. otakii (85 and 99 for the artificial and natural reefs, respectively) and 200 S. schlegelii ( 94 and 106 for the artificial and natural reefs, respectively) individuals were used for carbon and nitrogen isotopic analysis. Result of the MANOVA test showed notable discrepancies on both isotopic signatures between species and habitat types $(p<$ 0.05 for all cases), both of which also had strong interactions with seasons ( $p<0.05$ for both cases). Unexpected, relationships between SL and either $\delta^{13} \mathrm{C}$ or $\delta^{15} \mathrm{~N}$ were not significant for both species at each habitat type ( $p>0.05$ for all cases).

The isotopic characteristics of each species across seasons were displayed in Table 2. Generally, S. schlegelii exhibited more enriched isotopic signatures than $H$. otakii (ANOVA, $p<0.05$ ) at both reef sites, with one exception that no significant difference was detected for $\delta^{13} \mathrm{C}$ at the artificial reef. For S. schlegelii, both the $\delta^{13} \mathrm{C}$ and $\delta{ }^{15} \mathrm{~N}$ values were significantly lower at the artificial reef $(-18.42 \pm 0.38 \%$ and $13.97 \pm 0.53 \%$ o than at the natural reef $(-18.04 \pm 0.5 \%$ and $14.11 \pm 0.48 \%$ ) (ANONA, $p<0.05$ for both cases). In contrary, no significant spatial differences were observed for $H$. otakii on either the $\delta^{13} \mathrm{C}(-18.55 \pm 0.57 \%$ and

Table 1

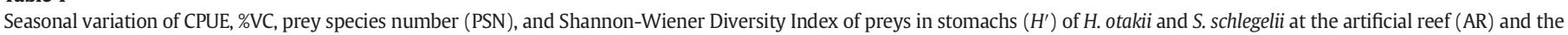
natural reef (NR) in Yellow Sea, China (2017-2018), where * represents significant difference within two reef types.

\begin{tabular}{|c|c|c|c|c|c|c|c|c|c|c|c|c|c|c|c|c|}
\hline \multirow[t]{3}{*}{ Season } & \multicolumn{8}{|l|}{ H. otakii } & \multicolumn{8}{|l|}{ S. schlegelii } \\
\hline & \multicolumn{4}{|l|}{$\mathrm{AR}$} & \multicolumn{4}{|l|}{ NR } & \multicolumn{4}{|l|}{$\mathrm{AR}$} & \multicolumn{4}{|l|}{$\mathrm{NR}$} \\
\hline & CPUE & $\% \mathrm{VC}$ & PSN & $H^{\prime}$ & CPUE & $\% \mathrm{VC}$ & PSN & $H^{\prime}$ & CPUE & $\% \mathrm{VC}$ & PSN & $H^{\prime}$ & CPUE & $\% \mathrm{VC}$ & PSN & $H^{\prime}$ \\
\hline Spring & $95.7^{*} \pm 45.2$ & $39.02 \%$ & 14 & 1.9 & $211 \pm 154.2$ & $35.53 \%$ & 18 & 2.11 & $347.5 \pm 179.7$ & $35.82 \%$ & 13 & 2.21 & $221.2 \pm 127.1$ & $51.09 \%$ & 13 & 2.13 \\
\hline Summer & $92.1 \pm 77.4$ & $47.17 \%$ & 11 & 1.78 & $132.9 \pm 72.5$ & $30.77 \%$ & 13 & 1.88 & $147.7 \pm 131.7$ & $92.59 \%$ & 4 & 1.19 & $253.6 \pm 79.7$ & $75 \%$ & 7 & 1.48 \\
\hline Fall & $442.4 \pm 216.3$ & $15.07 \%$ & 15 & 2.05 & $394.4 \pm 145.5$ & $10.20 \%$ & 21 & 2.44 & $770.7^{*} \pm 358.7$ & $26.15 \%$ & 13 & 2.08 & $412.8 \pm 93.8$ & $29.07 \%$ & 17 & 2.33 \\
\hline Winter & $33.6 \pm 33.3$ & 0 & 10 & 1.67 & $85.4 \pm 83.3$ & 0 & 12 & 1.85 & $203.6^{*} \pm 139.5$ & $7.14 \%$ & 6 & 1.55 & $37.9 \pm 28.3$ & 0 & 9 & 1.68 \\
\hline Mean & $165.9 \pm 186.5$ & $25.23 \%$ & 12.5 & 1.85 & $205.9 \pm 135.9$ & $19.13 \%$ & 16 & 2.07 & $367.4^{*} \pm 281.7$ & $40.43 \%$ & 9 & 1.76 & $231.4 \pm 153.8$ & $38.79 \%$ & 11.5 & 1.91 \\
\hline
\end{tabular}




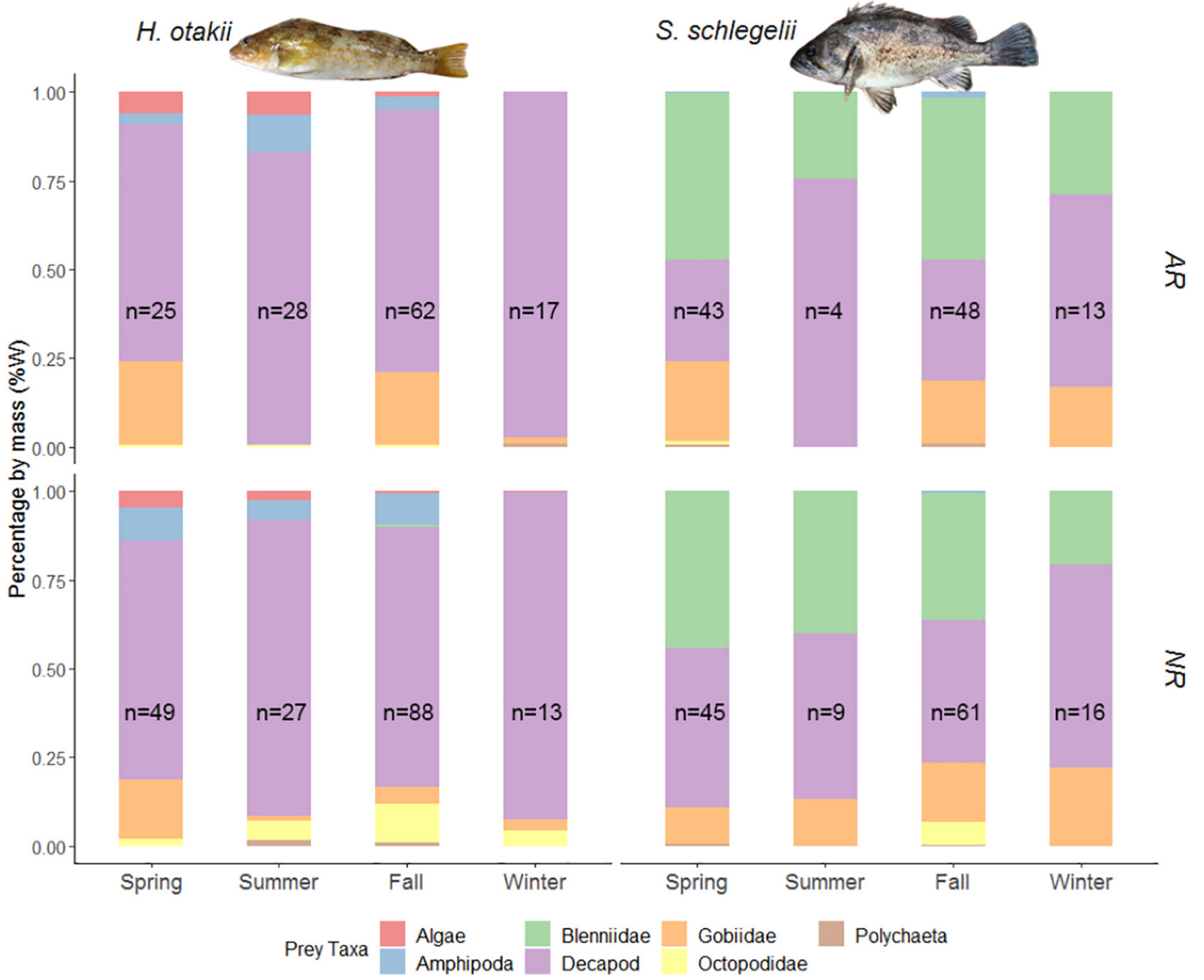

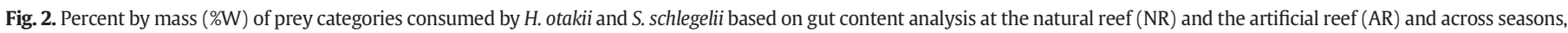
where " $n$ " represents numbers of informative stomachs.

$-18.46 \pm 0.55 \%$ ofor the artificial and natural reefs, respectively) or the $\delta^{15} \mathrm{~N}(13.03 \pm 0.54 \%$ and $13.19 \pm 0.55 \%$ ofor the artificial and natural reefs, respectively).

The isotopic values of potential prey groups (e.g., algae, Decapod, Gobiidae, and Amphipods) displayed seasonal variations, though species composition of each group might vary by seasons (Table $\mathrm{S2}$ ). The isospace plot of both $H$. otakii and S. schlegelii together with their potential food resources was exhibited in Fig. 3, where the mixture data were inside of the source polygon made of each prey taxa, supporting that our MixSIAR estimation on diet proportions make sense.

Our MixSIAR results (as exhibited in Fig. 4) revealed Decapod and Amphipoda were two typical prey taxa for H. otakii, with Gobiidae and algae acting as supplement food. Differently, Blenniidae and Gobiidae were principal prey of $S$. schlegelii, which also showed different degree of dependence on Decapod and Amphipoda. In terms of the prey taxa contribution to $H$. otakii at different reef types, prey taxa were more diverse at the natural reef than the artificial reef, especially in summer and fall. There were more prey taxa with estimated contributions of median over 3\% at natural reefs (6 vs. 4 in summer; 5 vs. 4 in fall; Fig. 4). Overall, the prey taxa contributions were more evenly for $H$. otakii at the artificial reef.

Contribution pattern of prey to $S$. schlegelii varied by habitat types and across seasons. For instance, Amphipoda's contribution to the S. schlegelii was higher at the artificial reef in spring and summer, with contribution of median 0.201 and 0.254 , together with $25 \%-75 \%$ Bayesian credible interval $[\mathrm{CI}] 0.015-0.303$ and $0.152-0.307$, respectively, whereas the depletion of Polychaete was greater at the artificial reef, with $0.297,0.054-0.417[\mathrm{CI}]$ and $0.43,0.002-0.522[\mathrm{CI}]$ in spring and summer, respectively. Moreover, S. schlegelii displayed reliance on Octopidae to some extent $(0.105,0.044-0.184$ [CI]) at the natural reef in fall and preyed more on Decapod at the natural reef $(0.455$, $0.348-0.566[\mathrm{CI}])$ relative to their artificial counterpart $(0.237$, $0.168-0.319[\mathrm{CI}])$ in winter. The summary statistics of MixSIAR models on both species across seasons were exhibited in Table S3.

Table 2

Standard length (SL) and Stable isotopic characteristics of H. otakii and S. schlegelii at the artificial reef (AR) and the natural reef (NR) in different seasons.

\begin{tabular}{|c|c|c|c|c|c|c|c|c|c|}
\hline \multirow[t]{2}{*}{ Date } & \multirow[t]{2}{*}{ Species } & \multicolumn{4}{|l|}{$\mathrm{AR}$} & \multicolumn{4}{|l|}{ NR } \\
\hline & & $\mathrm{n}$ & $\mathrm{SL}$ & $\delta^{13} \mathrm{C}$ & $\delta^{15} \mathrm{~N}$ & $\mathrm{n}$ & $\mathrm{SL}$ & $\delta^{13} \mathrm{C}$ & $\delta^{15} \mathrm{~N}$ \\
\hline \multirow[t]{2}{*}{ Spring } & H. otakii & 20 & $14.66 \pm 2.8$ & $-18.69 \pm 0.6$ & $13.06 \pm 0.6$ & 34 & $15.32 \pm 3.4$ & $-18.38 \pm 0.6$ & $13.3 \pm 0.5$ \\
\hline & S. schlegelii & 33 & $14.69 \pm 4.5$ & $-18.28 \pm 0.4$ & $14.15 \pm 0.5$ & 32 & $15.59 \pm 2.9$ & $-17.89 \pm 0.5$ & $14.14 \pm 0.5$ \\
\hline \multirow[t]{2}{*}{ Summer } & H. otakii & 24 & $12.44 \pm 2.4$ & $-18.84 \pm 0.5$ & $12.61 \pm 0.4$ & 26 & $15.96 \pm 4.7$ & $-18.53 \pm 0.5$ & $13.06 \pm 0.5$ \\
\hline & S. schlegelii & 21 & $15.09 \pm 4.5$ & $-18.38 \pm 0.3$ & $13.66 \pm 0.5$ & 26 & $16.31 \pm 3.7$ & $-18.13 \pm 0.4$ & $14.03 \pm 0.4$ \\
\hline \multirow[t]{2}{*}{ Fall } & H. otakii & 24 & $14.59 \pm 3.2$ & $-18.21 \pm 0.5$ & $13.37 \pm 0.5$ & 27 & $14.67 \pm 3.0$ & $-18.61 \pm 0.7$ & $13.09 \pm 0.6$ \\
\hline & S. schlegelii & 26 & $17.27 \pm 6.7$ & $-18.69 \pm 0.4$ & $14.03 \pm 0.6$ & 32 & $19.51 \pm 6.9$ & $-18.26 \pm 0.5$ & $14.17 \pm 0.6$ \\
\hline \multirow[t]{2}{*}{ Winter } & H. otakii & 17 & $14.02 \pm 2.5$ & $-18.47 \pm 0.4$ & $13.12 \pm 0.3$ & 12 & $16.33 \pm 3.3$ & $-18.2 \pm 0.3$ & $13.44 \pm 0.4$ \\
\hline & S. schlegelii & 14 & $22.3 \pm 4.6$ & $-18.32 \pm 0.4$ & $13.9 \pm 0.2$ & 16 & $19.54 \pm 5.5$ & $-17.77 \pm 0.5$ & $14.07 \pm 0.3$ \\
\hline
\end{tabular}



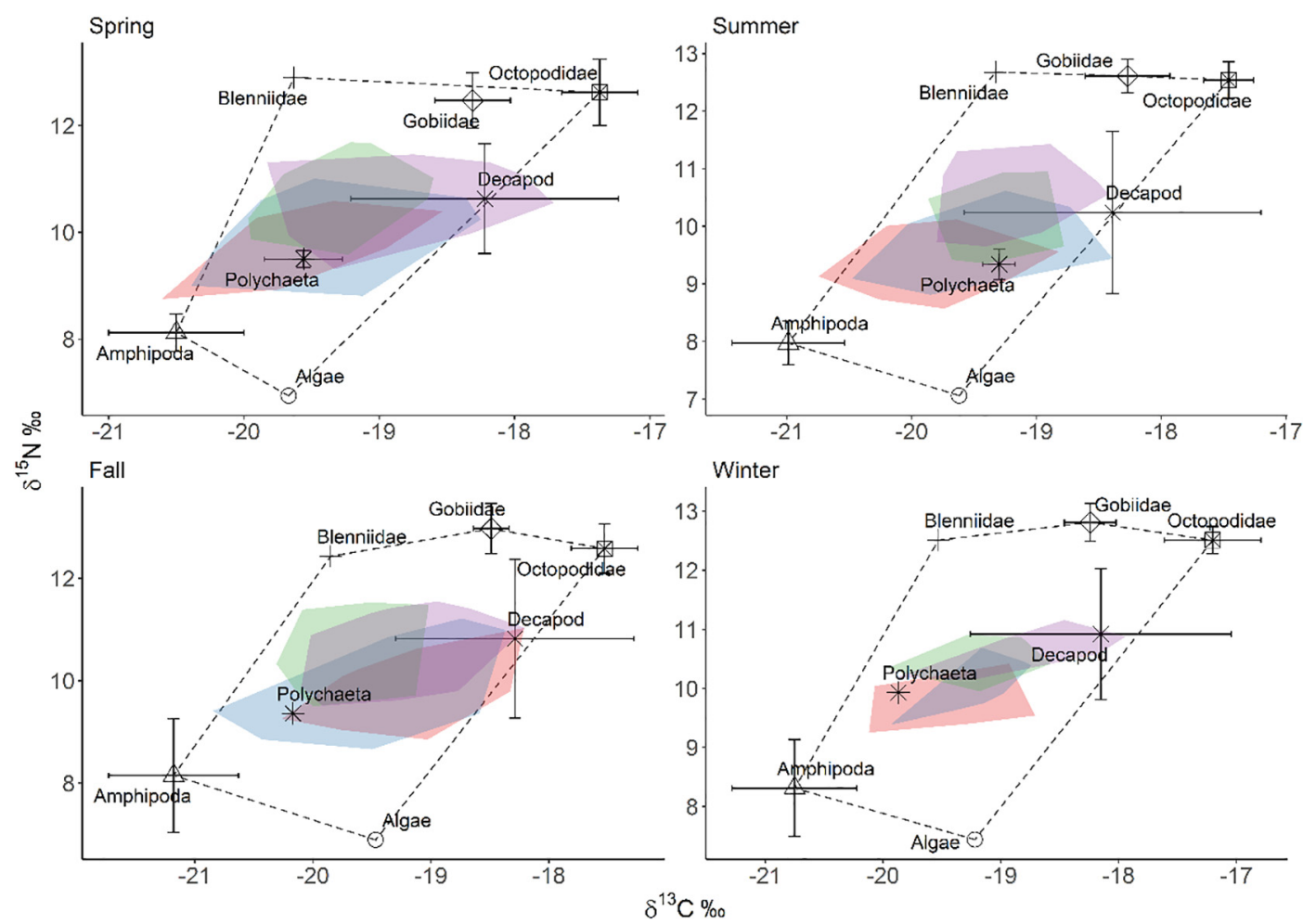

Prey Taxa $\triangle$ Algae $\stackrel{+}{\triangle \text { Amphipoda }} \times$ Decapod $*$ Gobiidae $\otimes$ Octopodidae

Predator $\square$ H. ota at AR $\square$. ota at NR $\square$ S. sch at AR $\square$ S. sch at NR

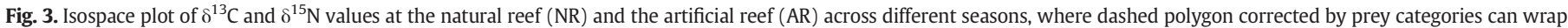
colored polygon made up of TDF corrected data of both S. schlegelii (S. sch) and H. otakii (H. ota).

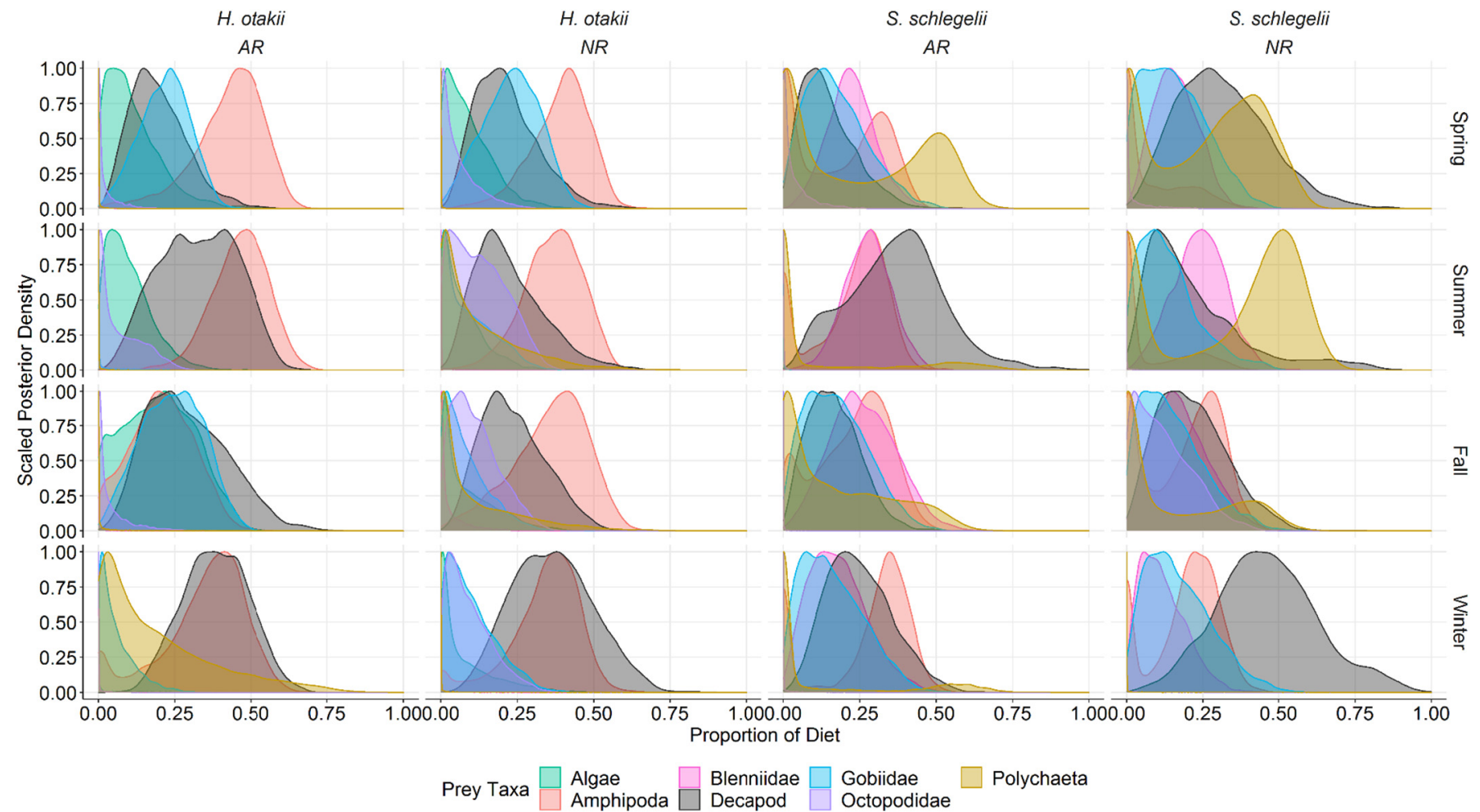

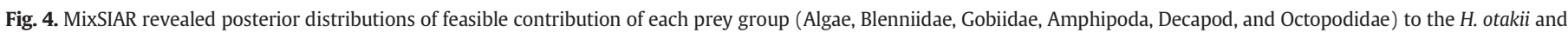
S. schlegelii at the natural reef and the artificial reef across different seasons. 
Table 3

Seasonal variations of SEAc values and \%OA values of/between S. schlegelii and H. otakii at the natural reef (NR) and the artificial reef (AR).

\begin{tabular}{|c|c|c|c|c|c|c|}
\hline \multirow[t]{2}{*}{ Date } & \multicolumn{3}{|l|}{ NR } & \multicolumn{3}{|l|}{ AR } \\
\hline & H. otakii & S. schlegelii & $\% \mathrm{OA}$ & H. otakii & S. schlegelii & $\% \mathrm{OA}$ \\
\hline Spring & 0.87 & 0.89 & $37.2 \%$ & 0.80 & 0.58 & $23.0 \%$ \\
\hline Summer & 0.73 & 0.54 & $28.3 \%$ & 0.61 & 0.44 & $25.2 \%$ \\
\hline Fall & 1.21 & 0.82 & $38.8 \%$ & 0.77 & 0.72 & $33.0 \%$ \\
\hline Winter & 0.32 & 0.31 & $27.5 \%$ & 0.45 & 0.28 & $13.5 \%$ \\
\hline
\end{tabular}

\subsection{Niche width and niche overlap}

Both S. schlegelii and $H$. otakii generally displayed higher niche width at the natural reef (SEAc: $0.64 \pm 0.27$ vs. $0.78 \pm 0.37$, on seasonal average) compared the artificial reef (SEAc: $0.51 \pm 0.19$ vs. $0.66 \pm 0.16$, on seasonal average) (ANOVA, $p<0.05$ for both cases). Furthermore, $H$. otakii generally displayed higher SEAc value than S. schlegelii at the artificial reef (ANOVA, $p<0.05$ ), whereas marked interspecific difference of SEAc value was absent at the natural reef (ANOVA, $p>0.05$ ). No significant niche overlap was observed between $H$. otakii and $S$. schlegelii across all seasons at both reef types $(\% \mathrm{OA}<60 \%)$, but \%OA were lower at the artificial reef (seasonal average $\% \mathrm{OA}=23.7 \pm 8.06 \%$ ) than at the natural reef (seasonal average $\% \mathrm{OA}=33.0 \pm 5.89 \%)$. The maximum niche overlap was present in spring $(\% \mathrm{OA}=33.0 \%$ and $38.8 \%$ for the artificial and natural reefs, respectively), while the minimum was present in winter $(\% \mathrm{OA}=13.5 \%$ and $27.5 \%$ for the artificial and natural reefs, respectively) at both sites. The seasonal variation of SEAc and \%OA for both species at the natural reef and the artificial reef are displayed in Table 3 and Fig. 5.

\section{Discussion}

Based on GCA and SIA adopted on H. otakii and S. schlegelii in four seasons, differences on trophic ecology within two species and between the natural reef and the artificial reef were examined, reflecting that the habitat-specific effects on the trophic ecology of both reef species. Information of the trophic ecology of two reef-associated fishes provided in our study can not only give insights to the habitat quality of the artificial reefs in supporting biological and ecological needs of large reef predators, but also allow for a deeper understanding of the trophic diversity and the stability of community structures.

\subsection{Fish biomass comparisons between habitats types}

Comparable or even higher biomass at the artificial reef were observed for $\mathrm{H}$. otakii and S. schlegelii relative to those at the natural reef, supporting the verified conclusion that the artificial reef can be an efficient tool in enhancing reef fish biomass (Bohnsack et al., 1994; Lima et al., 2019; Lowry et al., 2014). This result provides direct evidences that artificial reefs are suitable habitats for both reef-associated species in the coast of Yellow Sea, China. Many previous studies have demonstrated habitat complexity generally is positively associated with the abundance, biomass and richness of reef-associated fish assemblage (Hackradt et al., 2011; Komyakova et al., 2013; Lowry et al., 2014). The introduced hard substrate improved the complexity of habitat structure, such as general complexity, vertical relief and presence of small holes or crevices, which reef fishes and their benthic prey can used as shelters (Bohnsack, 1989; Komyakova and Swearer, 2019; Leitao et al., 2007; Scarcella et al., 2011). Moreover, the rough rock surface can also be colonized by algae and sessile filter feeders, which promote the pelagic organic matter flux towards benthic community because of their strong filtration ability (Cresson et al., 2014). Hence,
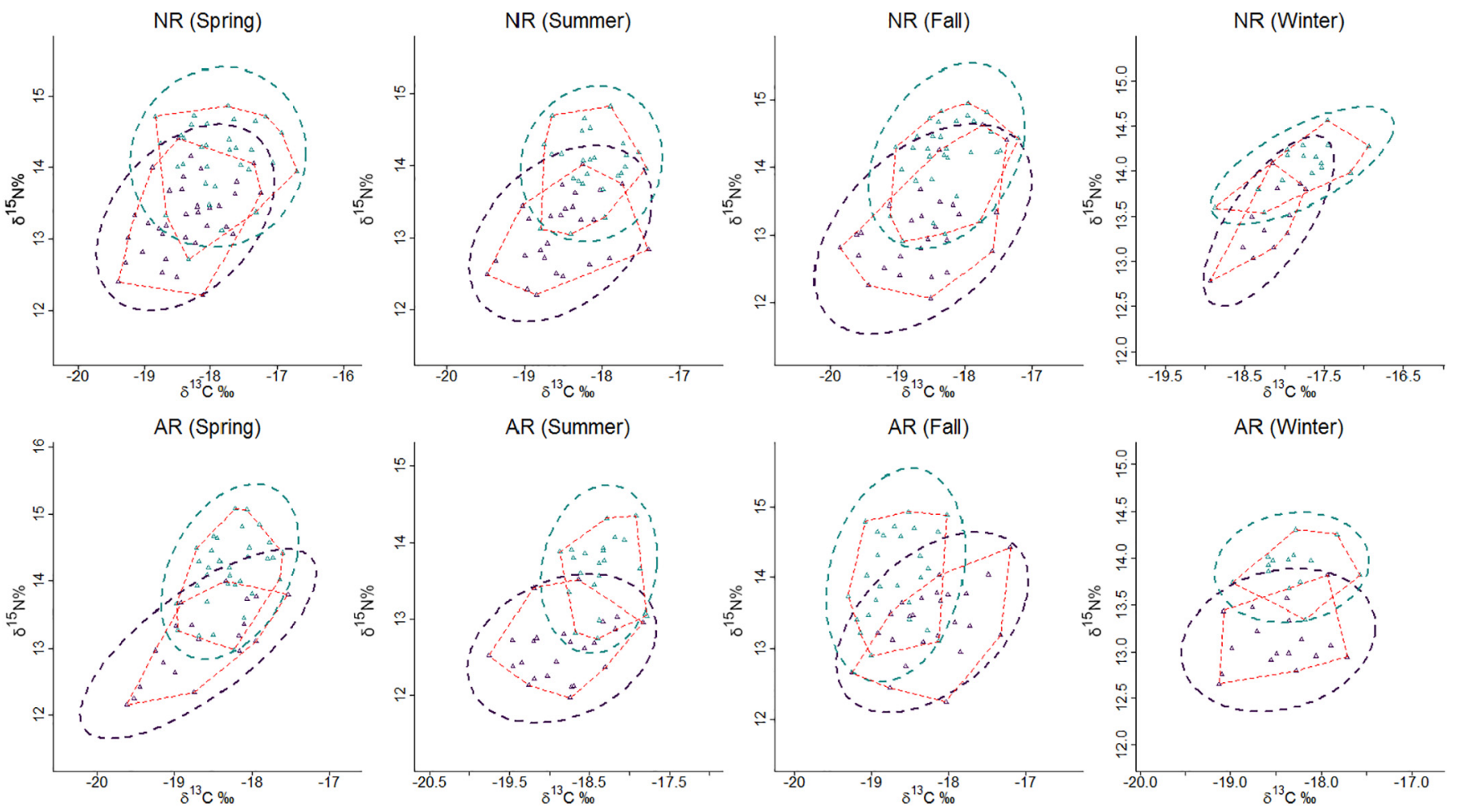

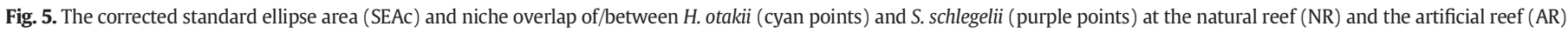

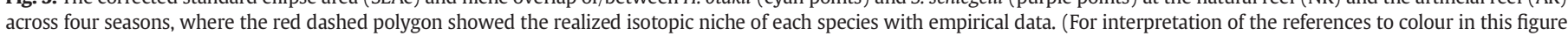
legend, the reader is referred to the web version of this article.) 
the increased primary or secondary production would transfer along the trophic network, which would facilitate the upper level predatory fish in the end.

\subsection{Interspecific and spatial differences on diet composition}

Based on GCA, both species displayed diverse feeding choices, with at least 28 prey items identified in H. otakii and 21 in S. schlegelii, supporting the conclusion that they are opportunistic carnivorous predators (Wu et al., 2018; Zhang et al., 2018). Decapods were observed to be most selected for by $H$. otakii at both sites, even though proportion of the diet represented by prey items within this category varied by habitat types, while $S$. schlegelii displayed a largely dependence of Gobiidae and Blenniidae irrelevant to habitat types. Our result is consistent with previous studies on trophic ecology of $H$. otakii and S. schlegelii, reporting that these two species were both shrimp and fish feeders, where H. otakii preyed more on Decapod while S. schlegelii relied more on teleosts (Kwak et al., 2005; Wu et al., 2018; Zhang et al., 2018).

Notable spatial disparities were detected on \%VC values, prey diversity, and gut content compositions for both species, reflecting to some extent the environmental condition and prey availability varied between the artificial and natural habitats. The occurrence of vacant stomachs is likely associated to either the shortage of available food supply or ceasing forging because of the unfavorable external conditions. In both $\mathrm{H}$. otakii and S. schlegelii, high \%VC was observed in spring and summer, while lower values were detected after summer. This can be explained by that S. schlegelii and $H$. otakii are temperate fishes which may reduce foraging frequency when facing dissatisfactory environmental conditions. The extreme high \%VC values (up to $80 \%$ and $90 \%$ at the natural reef and the artificial reef, respectively) of S. schlegelii were identified in summer. The high vacuity was less possibly caused by the food scarcity considering that the bloom of macroalgae and phytoplankton in spring and summer can supply substantial organic matters to secondary consumers. Therefore, the high \%VC values in summer might be explained mainly by high temperature and low dissolved oxygen at bottom water layer, which drastically inhibited the feeding behavior of S. schlegelii. On another hand, the natural reef displayed a lower \%VC than the artificial reef, suggesting that the natural reef provided more flexible conditions (e.g. more micro-habitats or food source) for predatory fishes to cope with poor conditions.

Diets of both species were more diverse at the natural reef than the artificial reef. On one hand, this may suggest natural reefs may support a broader feeding choice than artificial habitats do. On the other hand, a diverse diet of predators represents not only an omnivore or an opportunism feeding strategy but also a lower supplement of preferred prey items (Svanback and Bolnick, 2007). A predatory with preferential prey taxa may have to expand their feeding range to fulfill their food requirements. James et al. (2020) has reported more diverse food resources were exploited at the restored oyster reef than their natural counterparts, implying that resources use variability was caused by the lower productivity at the restored habitats. However, cases may be different and not consistent in this study, due to the high vacuity for each species in particular seasons. For instance, if the food supply is not sufficient for $H$. otakii in spring and summer, which assums to be the main explanation of the vacant stomachs at both sites, the higher prey diversity at the natural reef would suggest more varied feeding choice than that at the artificial reef. Instead, lower vacuity for each species can be indicative of a relatively adequate supply of food for them, and the lower prey diversity in fall and winter at the artificial reef probably reflects $H$. otakii can derive enough energy from particular prey items, without necessary to seek for other food resources.

Habitat differences in stomach contents were observed in $\mathrm{H}$. otakii across all seasons except winter, while absent for $S$. schlegelii, which relied mainly on Gobiidae and Blenniidae and partly on Decapod independent of habitat types. The principal differences for $\mathrm{H}$. otakii were mainly contributed by proportion variation of fish and Decapod, implying distinct prey (fish and Decapod) availability associated with the habitats. Previous studies have reported that artificial reefs may support distinct community structure compared to natural reefs, taking account of impacting factors such as habitats complexity (Connell, 1998; Mills et al., 2017), reef ages (Perkol-Finkel and Benayahu, 2004, 2007), hydrologic condition (Feyrer et al., 2011; Fowler and Booth, 2012) and the distance between the artificial and natural reefs (Sanabria-Fernandez et al., 2018; Strelcheck et al., 2005). In this study, higher-relief characteristics, much bigger reef area, and more densely coverage of macro algae (especially in summer) were observed by the diving observation at the natural reef relative to the artificial reef (data not shown), which may also be limited in relatively flat layout and short deployed duration. Result of this work was consistent with the work by Carvalho et al. (2013), which suggested that epibenthic assemblages differed between artificial reefs deployed more than 16 year and natural reefs in terms of composition, structure and trophic function. Similarly, Page et al. (2007) also observed a different amphipod assemblage in the diet of a resident reef fish (Oxylebius pictus) at the artificial reef and the natural reef based on the GCA. Schwartzkopf et al. (2017) and Brewton et al. (2020) reported higher diversity of prey items in the natural reef and little overlap in prey species consumption between the natural and artificial reefs in Red Snapper (L. campechanus). As preys can affect the quality and quantity of food available to the consumer (also called "bottom-up" process), habitat related variability in prey resources would probably lead to the specific habitat related consumers assemblages. Nowadays, researches on community structure at the artificial reef have paid more attention to the high mobility or relative larger species, overlooking those less conspicuous species which are common but hard to catch or quantify with standing techniques, especially in water with low transparency (Sanabria-Fernandez et al., 2018). This work highlights the appropriateness of GCA method in comparing the role of artificial reefs on prey assemblages to their natural counterparts, albeit with many disadvantages. More techniques therefore are still awaited in future studies to accurately describe the assemblages of prey.

Despite allowing for the identification of what a targeted fish actually consumed recently, the GCA could not reveal dietary information in long terms (Ahlbeck et al., 2012; Hyslop, 1980; Layman et al., 2012; Peterson and Fry, 1987; Phillips and Eldridge, 2006; Votier et al., 2003). Hence, in order to incorporate the uncertainties related to multiple sources and obtain more robust results on feeding ecology of both species, SIA coupled with Bayesian mixing models was introduced to complement the GCA (Parnell et al., 2010; Phillips, 2012).

Source contribution estimates are important for understanding trophic pathways, as well as identifying essential food resources to consumers. Based on the MixSIAR model, spatial and interspecific differences on stable isotopic values were disclosed, revealing that Decapod and Amphipoda were major contributors of $H$. otakii diet, while S. schlegelii mainly depend on fish, Decapod and Amphipoda. This result is generally consistent with GCA results, such as the overall contribution of each prey taxa. Nevertheless, disparities also occurred within the two methods. For example, algae accounted for a certain degree of proportion to the $H$. otakii diet based on MixSIAR, while GCA result only claimed a negligible role of algae; MixSIAR revealed potential contributions of Amphipoda prey to the diets of S. schlegelii, where the importance of this prey category was not mirrored by GCA. Moreover, habitat- specific effects on sources contributions to $S$. schlegelii were revealed by the MixSIAR, reflecting the reliance of Blennidae, Gobiidae, and Amphipoda varied by habitat types. It appears likely that the GCA may have inflated the importance of some prey items, which are easier to identify due to persistent hard structures, such as crabs and shrimps. Additionally, the digestion ability may be varied among species, which would also bias the actual diet difference within species. And the loss of unknown preys caused by stomach eversion during collection can also obscure the GCA results. Hence, the quantification for contribution estimate of each source derived from MixSIAR might be more representative in reflecting the potential prey availability difference between the natural and artificial reefs. 


\subsection{Trophic niche width and niche overlap comparison}

Niche theory is one of the commonly used theories to explain the mechanism of coexistence and competition between species, in which niche width and niche overlap are important for understanding the status, role and inter-specific relationships of species in the community (Alley, 1982; Pocheville, 2015). In current study, isotopic niches represented by the SEAc indicated trophic diversity was higher at the natural reef than at the artificial reef for either of species, which is similar to the findings reported for red snapper (L. campechanus) at the Gulf of Mexico (Schwartzkopf et al., 2017). These findings might on another aspect reflect that natural reefs play better roles in supporting the predators by exploiting higher diverse array of prey taxa. Furthermore, although low niche overlap values $(\% \mathrm{OA}<0.6)$ were detected between two species at both reef sites, our results still showed higher values at the natural than artificial reef, indicating larger overlap of the food resources. The larger niche overlap at the natural reef might be due to that both species have to increase their dietary diversity in response to low prey availability and relatively stronger mutual exploitation on similar food resources (Batzer and Boix, 2016; Schindler et al., 1997; Svanback and Bolnick, 2007; Vander Zanden et al., 2000). It seems likely the case at the artificial reef is that either $H$. otakii or S. schlegelii can catch sufficient prey items with preference, it may be un-imperative for them to seek for higher diet diversification. As the comparable biomass of both species (even higher for S. schlegelii) at the artificial reef, a conclusion can thus be drawn that the quality of habitat at the artificial reef may be comparable or even better in supporting these two species livelihood, for the environmental fitness, sufficient food and to less extent interspecific food overlap.

In ecology, the competitive exclusion principle states that two species competing for same resources can only coexist when there is niche differentiation (Hardin, 1960; Pocheville, 2015), which generally include partitioning of food and space (Michael et al., 2005). Our result revealed no significant niche overlap between the two upper level reefassociated fishes, which may give insights into the mechanism of their coexistence in artificial reefs. Similar findings have also been reported by Dance et al. (2018), which revealed Gray triggerfish (Balistes capriscus) had larger SEAc, with no significant overlap across all size classes relative to red snapper (L. campechanus) at the artificial reef in the northwest Gulf of Mexico, which probably be due to the different feeding strategies. Mablouke et al. (2013) also observed significant niche overlap among three commercial fish species at artificial reefs in south-western Indian Ocean caused by resource partitioning. Nevertheless, we should also be aware that, as the ecological niche occupied by one species also depend on other ecological factors such as population size, climate factors, landscape characteristics, disease (Pocheville, 2015; Svanback and Bolnick, 2007), which means the trophic interaction would be changed once the species' niche modified. Therefore, to uncover the effect of artificial reefs on the trophic interaction of reef-associated predators in long terms, persisting surveillance and corresponding follow-up studies are warranted.

\section{Conclusion}

Our field investigation in the nearshore reef habitat of Yellow Sea, China showed the biomass of predatory fishes at the artificial reef was comparable (H. otakii) to or higher (S. schlegelii) than those at the natural reef, implying environment fitness of the artificial reef in situ. Besides, the different prey availability between two reef habitats was revealed based on GCA and SIA analysis, and we detected more diverse trophic niches but relative lower food resource partitioning degree at the natural reef. Overall, our results implied that artificial reefs can be an alternative management practice in providing high quality habitat for predatory reef-associated fishes and accommodate their coexistence.

\section{CRediT authorship contribution statement}

Rongliang Zhang: Formal analysis, original draft writing-; Qianqian Zhang: Writing - review \& editing, Hui Liu: Data curation, Validation; Jianmin Zhao: Supervision, Funding acquisition, Writing - review \& editing; Hua Zhang: Supervision, Writing - review \& editing;

\section{Declaration of competing interest}

The authors declare that they have no known competing financial interests or personal relationships that could have appeared to influence the work reported in this paper.

\section{Acknowledgements}

We thank all those who helped in the field and laboratory works, including but not limited to Yemin He for the help in fishery investigation and sample collection, Haozhi Sui for the identification of prey items in stomachs and Yang Tan for the isotopic analysis. This project was supported by grants from the Strategic Pilot Project of Chinese Academy of Sciences (XDA23050303), National Natural Science Foundation of China (41806150), the Youth Innovation Promotion Association, Chinese Academy of Sciences (No. 2019216) and TwoHundred Talents Plan of Yantai (Y839081021).

\section{Appendix A. Supplementary data}

Supplementary data to this article can be found online at https://doi. org/10.1016/j.scitotenv.2021.148250.

\section{References}

Ahlbeck, I., Hansson, S., Hjerne, O., 2012. Evaluating fish diet analysis methods by individual-based modelling. Can. J. Fish. Aquat. Sci. 69 (7), 1184-1201. https://doi. org/10.1139/f2012-051.

Alley, T.R., 1982. Competition theory, evolution, and the concept of an ecological niche. Acta Biotheor. 31 (3), 165-179. https://doi.org/10.1007/Bf01857239.

Baine, M., 2001. Artificial reefs: a review of their design, application, management and performance. Ocean Coast. Manag. 44 (3), 241-259. https://doi.org/10.1016/S09645691(01)00048-5.

Bascompte, J., Melian, C.J., Sala, E., 2005. Interaction strength combinations and the overfishing of a marine food web. Proc. Natl. Acad. Sci. USA 102 (15), 5443-5447. https://doi.org/10.1073/pnas.0501562102.

Batzer, D., Boix, D., 2016. Invertebrates in Freshwater Wetlands. Springer International Publishing, Berlin.

Bohnsack, J.A., 1989. Are high-densities of fishes at artificial reefs the result of habitat limitation or behavioral preference. B Mar Sci 44 (2), 631-645. https://doi.org/10.1515/ botm.1989.32.2.181.

Bohnsack, J.A., Harper, D.E., Mcclellan, D.B., Hulsbeck, M., 1994. Effects of reef size on colonization and assemblage structure of fishes at artificial reefs off southeastern Florida, USA. B Mar Sci 55 (2-3), 796-823. https://doi.org/10.1515/botm.1994.37.5.483.

Brewton, R.A., Downey, C.H., Streich, M.K., Wetz, J.J., Ajemian, M.J., Stunz, G.W., 2020. Trophic ecology of red snapper Lutjanus campechanus on natural and artificial reefs: interactions between annual variability, habitat, and ontogeny. Mar. Ecol. Prog. Ser. 635, 105-122. https://doi.org/10.3354/meps13210.

Calkins TP, 1961. Measures of population density and concentration of fishing effort for yellowfin and skipjack tuna in the eastern Tropical Pacific Ocean 1951-1959. Inter American Tropical Tuna Commission Bulletin, 6(3): 71-151. doi:oai:generic.eprints. org:2580/core331.

Carr, M.H., Hixon, M.A., 1997. Artificial reefs: the importance of comparisons with natural reefs. Fisheries 22 (4), 28-33. https://doi.org/10.1577/1548-8446(1997)022<0028: Artioc $>2.0 . \mathrm{CO}_{2}$.

Carvalho, S., Moura, A., Curdia, J., Cancela da Fonseca, L., Santos, M.N., 2013. How complementary are epibenthic assemblages in artificial and nearby natural rocky reefs? Mar. Environ. Res. 92, 170-177. https://doi.org/10.1016/j.marenvres.2013.09.013.

Connell, S.D., 1998. Effects of predators on growth, mortality and abundance of a juvenile reef-fish: evidence from manipulations of predator and prey abundance. Mar. Ecol. Prog. Ser. 169, 251-261. https://doi.org/10.3354/meps169251.

Cresson, P., Ruitton, S., Harmelin-Vivien, M., 2014. Artificial reefs do increase secondary biomass production: mechanisms evidenced by stable isotopes. Mar. Ecol. Prog. Ser. 509 (5), 15-26. https://doi.org/10.3354/meps10866.

Cresson, P., Le Direach, L., Rouanet, E., Goberville, E., Astruch, P., Ourgaud, M., HarmelinVivien, M., 2019. Functional traits unravel temporal changes in fish biomass production on artificial reefs. Mar. Environ. Res. 145, 137-146. https://doi.org/10.1016/j. marenvres.2019.02.018. 
Dance, K.M., Rooker, J.R., Shipley, J.B., Dance, M.A., Wells, R.J.D., 2018. Feeding ecology of fishes associated with artificial reefs in the northwest Gulf of Mexico. PLoS One 13 (10), e0203873. https://doi.org/10.1371/journal.pone.0203873.

Feyrer, F., Newman, K., Nobriga, M., Sommer, T., 2011. Modeling the effects of future outflow on the abiotic habitat of an imperiled estuarine fish. Estuar. Coasts 34 (1), 120-128. https://doi.org/10.1007/s12237-010-9343-9.

Fowler, A.M., Booth, D.J., 2012. Evidence of sustained populations of a small reef fish on artificial structures. Does depth affect production on artificial reefs? J. Fish Biol. 80 (3), 613-629. https://doi.org/10.1111/j.1095-8649.2011.03201.x.

Guzzo, M.M., Haffner, G.D., Legler, N.D., Rush, S.A., Fisk, A.T., 2013. Fifty years later: trophic ecology and niche overlap of a native and non-indigenous fish species in the western basin of Lake Erie. Biol. Invasions 15 (8), 1695-1711. https://doi.org/10.1007/s10530012-0401-z.

Hackradt, C.W., Felix-Hackradt, F.C., Garcia-Charton, J.A., 2011. Influence of habitat structure on fish assemblage of an artificial reef in southern Brazil. Mar. Environ. Res. 72 (5), 235-247. https://doi.org/10.1016/j.marenvres.2011.09.006.

Hardin, G., 1960. The competitive exclusion principle. Science 131 (3409), 1292-1297. https://doi.org/10.1126/science.131.3409.1292.

Heithaus, M.R., Vaudo, J.J., Kreicker, S., Layman, C.A., Krutzen, M., Burkholder, D.A., Gastrich, K., Bessey, C., Sarabia, R., Cameron, K., Wirsing, A., Thomson, J.A., DunphyDaly, M.M., 2013. Apparent resource partitioning and trophic structure of largebodied marine predators in a relatively pristine seagrass ecosystem. Mar. Ecol. Prog. Ser. 481, 225-237. https://doi.org/10.3354/meps10235.

Hothorn, T., Bretz, F., Westfall, P., 2008. Simultaneous inference in general parametric models. Biom. J. 50 (3), 346-363. https://doi.org/10.1002/bimj.200810425.

Hyslop, E.J., 1980. Stomach contents analysis - a review of methods and their application. J. Fish Biol. 17 (4), 411-429. https://doi.org/10.1111/j.1095-8649.1980.tb02775 x.

Jackson, A.L., Inger, R., Parnell, A.C., Bearhop, S., 2011. Comparing isotopic niche widths among and within communities: SIBER - Stable Isotope Bayesian Ellipses in R. J. Anim. Ecol 80 (3), 595-602. https://doi.org/10.1111/j.1365-2656.2011.01806.

James, W.R., Lesser, J.S., Litvin, S.Y., Nelson, J.A., 2020. Assessment of food web recovery following restoration using resource niche metrics. Sci. Total Environ. 711 (1), 134801. https://doi.org/10.1016/j.scitotenv.2019.134801.

Kang, K.-M., Shin, H.-O., 2006. Movement ranges and routes of black rockfish Sebastes schlegeli in summer and autumn from acoustic telemetry. Fish. Aquat. Sci. 9 (2), 91-96. https://doi.org/10.5657/fas.2006.9.2.091

Komyakova, V., Swearer, S.E., 2019. Contrasting patterns in habitat selection and recruitment of temperate reef fishes among natural and artificial reefs. Mar. Environ. Res. 143, 71-81. https://doi.org/10.1016/j.marenvres.2018.11.005.

Komyakova, V., Munday, P.L., Jones, G.P., 2013. Relative importance of coral cover, habitat complexity and diversity in determining the structure of reef fish communities. PLoS One 8 (12), e83178. https://doi.org/10.1371/journal.pone.0083178.

Kondoh, M., 2008. Building trophic modules into a persistent food web. Proc. Natl. Acad. Sci. USA 105 (43), 16631-16635. https://doi.org/10.1073/pnas.0805870105.

Kwak, S.N., Baeck, G.W., Klumpp, D.W., 2005. Comparative feeding ecology of two sympatric greenling species, Hexagrammos otakii and Hexagrammos agrammus in eelgrass Zostera marina beds. Environ. Biol. Fish 74 (2), 129-140. https://doi.org/10.1007/ s10641-005-7429-1.

Layman, C.A., Allgeier, J.E., 2020. An ecosystem ecology perspective on artificial reef production. J. Appl. Ecol. 57 (11), 2139-2148. https://doi.org/10.1111/1365-2664.13748.

Layman, C.A., Araujo, M.S., Boucek, R., Hammerschlag-Peyer, C.M., Harrison, E., Jud, Z.R., Matich, P., Rosenblatt, A.E., Vaudo, J.J., Yeager, L.A., Post, D.M., Bearhop, S., 2012. Applying stable isotopes to examine food-web structure: an overview of analytical tools. Biol. Rev. Camb. Philos. Soc. 87 (3), 545-562. https://doi.org/10.1111/j.1469185X.2011.00208.X.

Leitao, F., Santos, M.N., Monteiro, C.C., 2007. Contribution of artificial reefs to the diet of the white sea bream (Diplodus sargus). ICES J. Mar. Sci. 64 (3), 473-478. https:// doi.org/10.1093/icesjms/fsm027.

Lima, J.S., Zalmon, I.R., Love, M., 2019. Overview and trends of ecological and socioeconomic research on artificial reefs. Mar. Environ. Res. 145, 81-96. https://doi.org/ 10.1016/j.marenvres.2019.01.010.

Lowry, M.B., Glasby, T.M., Boys, C.A., Folpp, H., Suthers, I., Gregson, M., 2014. Response of fish communities to the deployment of estuarine artificial reefs for fisheries enhancement. Fish. Manag. Ecol. 21 (1), 42-56. https://doi.org/10.1111/fme.12048.

Mablouke, C., Kolasinski, J., Potier, M., Cuvillier, A., Potin, G., Bigot, L., Frouin, P., Jaquemet, S., 2013. Feeding habits and food partitioning between three commercial fish associated with artificial reefs in a tropical coastal environment. Afr. J. Mar. Sci. 35 (3), 323-334. https://doi.org/10.2989/1814232x.2013.829790.

Michael B, Colin RT, Harper JL, 2005. Ecology: From Individuals to Ecosystems 4th ed. Wiley-Blackwell, Oxford.

Mills, K.A., Hamer, P.A., Quinn, G.P., 2017. Artificial reefs create distinct fish assemblages. Mar. Ecol. Prog. Ser. 585, 155-173. https://doi.org/10.3354/meps12390.

Oksanen, J., Blanchet, F.G., Friendly, M., Kindt, R., Legendre, P., McGlinn, D., Minchin, P.R., Simpson, G.L., Solymos, P., Stevens, M.H.H., Szoecs, E., Wagner, H., 2020. vegan: Community Ecology Package. R package version 2.5-7 https://CRAN.R-project.org/package $=$ vegan

Page, H.M., Dugan, J.E., Schroeder, D.M., Nishimoto, M.M., Love, M.S., Hoesterey, J.C., 2007. Trophic links and condition of a temperate reef fish: comparisons among offshore oil platform and natural reef habitats. Mar. Ecol. Prog. Ser. 344, 245-256. https://doi.org/ 10.3354/meps06929.

Parnell, A.C., Inger, R., Bearhop, S., Jackson, A.L., 2010. Source partitioning using stable isotopes: coping with too much variation. PLoS One 5 (3), e9672. https://doi.org/ 10.1371/journal.pone.0009672.

Parnell, A., Jackson, A., 2013. siar: Stable Isotope Analysis in R. R package version 4.2. https://CRAN.R-project.org/package $=$ siar.
Parnell, A.C., Phillips, D.L., Bearhop, S., Semmens, B.X., Ward, E.J., Moore, J.W., Jackson, A.L., Grey, J., Kelly, D.J., Inger, R., 2013. Bayesian stable isotope mixing models. Environmetrics 24 (6), 387-399. https://doi.org/10.1002/env.2221.

Perkol-Finkel, S., Benayahu, Y., 2004. Community structure of stony and soft corals on vertical unplanned artificial reefs in Eilat (Red Sea): comparison to natural reefs. Coral Reefs 23 (2), 195-205. https://doi.org/10.1007/s00338-004-0384-z.

Perkol-Finkel, S., Benayahu, Y., 2007. Differential recruitment of benthic communities on neighboring artificial and natural reefs. J. Exp. Mar. Biol. Ecol. 340 (1), 25-39. https:// doi.org/10.1016/j.jembe.2006.08.008.

Peterson, B.J., Fry, B., 1987. Stable isotopes in ecosystem studies. Annu. Rev. Ecol. Syst. 18 293-320. https://doi.org/10.1146/annurev.es.18.110187.001453.

Phillips, D.L., 2012. Converting isotope values to diet composition: the use of mixing models. J. Mammal. 93 (2), 342-352. https://doi.org/10.1644/11-Mamm-S-158.1.

Phillips, D.L., Eldridge, P.M., 2006. Estimating the timing of diet shifts using stable isotopes. Oecologia 147 (2), 195-203. https://doi.org/10.1007/s00442-005-0292-0.

Phillips, D.L., Inger, R., Bearhop, S., Jackson, A.L., Moore, J.W., Parnell, A.C., Semmens, B.X., Ward, E.J., 2014. Best practices for use of stable isotope mixing models in food-web studies. Can. J. Zool. 92 (10), 823-835. https://doi.org/10.1139/cjz-2014-0127.

Pocheville, A., 2015. The ecological niche: history and recent controversies. In: Heams, T. Huneman, P., Lecointre, G., Silberstein, M. (Eds.), Handbook of Evolutionary Thinking in the Sciences. Springer Netherlands, Dordrecht, pp. 547-586.

Post, D.M., 2002. Using stable isotopes to estimate trophic position: models, methods, and assumptions. Ecology 83 (3), 703-718. https://doi.org/10.2307/3071875.

Sanabria-Fernandez, J.A., Lazzari, N., Riera, R., Becerro, M.A., 2018. Building up marine biodiversity loss: artificial substrates hold lower number and abundance of low occupancy benthic and sessile species. Mar. Environ. Res. 140, 190-199. https://doi.org/ 10.1016/j.marenvres.2018.06.010.

Scarcella, G., Grati, F., Polidori, P., Domenichetti, F., Bolognini, L., Fabi, G., 2011. Comparison of growth rates estimated by otolith reading of Scorpaena porcus and Scorpaena notata caught on artificial and natural reefs of the northern adriatic sea. Braz. J. Oceanogr. 59, 33-42. https://doi.org/10.1590/S1679-87592011000500006.

Schindler, D.E., Hodgson, J.R., Kitchell, J.F., 1997. Density-dependent changes in individua foraging specialization of largemouth bass. Oecologia 110 (4), 592-600. https://doi. org/10.1007/s004420050200.

Schoener, T.W., 1968. The anolis lizards of Bimini: resource partitioning in a complex fauna. Ecology 49 (4), 704-726. https://doi.org/10.2307/1935534.

Schwartzkopf, B.D., Langland, T.A., Cowan, J.H., 2017. Habitat selection important for red snapper feeding ecology in the Northwestern Gulf of Mexico. Mar. Coast. Fish 9 (1), 373-387. https://doi.org/10.1080/19425120.2017.1347117.

Simonsen, K.A., Cowan, J.H., Boswell, K.M., 2015. Habitat differences in the feeding ecology of red snapper (Lutjanus campechanus, Poey 1860): a comparison between artificial and natural reefs in the northern Gulf of Mexico. Environ. Biol. Fish 98 (3), 811-824. https://doi.org/10.1007/s10641-014-0317-9.

Stock BC, Semmens BX, 2016. MixSIAR GUI User Manual, https://github.com/brianstock/ MixSIAR. Version 3.1. doi:https://doi.org/10.5281/zenodo.1209993.

Strelcheck, A.J., Cowan, J.H., Shah, A., 2005. Influence of reef location on artificial-reef fish assemblages in the northcentral Gulf of Mexico. B Mar Sci 77 (3), 425-440. https:// doi.org/10.1029/2004JC002816.

Svanback, R., Bolnick, D.I., 2007. Intraspecific competition drives increased resource use diversity within a natural population. Proc. Royal Soc. B-Biol. Sci. 274 (1611), 839-844. https://doi.org/10.1098/rspb.2006.0198.

Tarnecki, J.H., Patterson, W.F., 2015. Changes in red snapper diet and trophic ecology following the deepwater horizon oil spill. Mar. Coast. Fish 7 (1), 135-147. https://doi. org/10.1080/19425120.2015.1020402.

Terborgh, J., Estes, J.A., 2010. Trophic Cascades: Predators, Prey and the Changing Dynamics of Nature. Island Press, Washington, pp. 2534-2535.

Vander Zanden, M.J., Shuter, B.J., Lester, N.P., Rasmussen, J.B., 2000. Within- and amongpopulation variation in the trophic position of a pelagic predator, lake trout (Salvelinus namaycush). Can. J. Fish. Aquat. Sci. 57 (4), 725-731. https://doi.org/ 10.1139/f00-011.

Votier, S.C., Bearhop, S., MacCormick, A., Ratcliffe, N., Furness, R.W., 2003. Assessing the diet of great skuas, Catharacta skua, using five different techniques. Polar Biol. 26 (1), 20-26. https://doi.org/10.1007/s00300-002-0446-z.

Wells, R.J.D., Cowan, J.H., Fry, B., 2008. Feeding ecology of red snapper Lutjanus campechanus in the northern Gulf of Mexico. Mar. Ecol. Prog. Ser. 361, 213-225. https://doi.org/10.3354/meps07425.

Williams, T.M., Estes, J.A., Doak, D.F., Springer, A.M., 2004. Killer appetites: assessing the role of predators in ecological communities. Ecology 85 (12), 3373-3384. https:// doi.org/10.1890/03-0696.

Wu, Z.X., Zhang, X.M., Dromard, C.R., Tweedley, J.R., Loneragan, N.R., 2018. Partitioning of food resources among three sympatric scorpionfish (Scorpaeniformes) in coastal waters of the northern Yellow Sea. Hydrobiologia 826 (1), 331-351. https://doi.org/ 10.1007/s10750-018-3747-0.

Zhang, Y., Xu, Q., Alos, J., Liu, H., Xu, Q., Yang, H., 2015. Short-term fidelity, habitat use and vertical movement behavior of the black rockfish Sebastes schlegelii as determined by acoustic telemetry. PLoS One 10 (9), e0134381. https://doi.org/10.1371/journal. pone.0134381.

Zhang, Y.Q., Xu, Q., Xu, Q.Z., Alos, J., Zhang, H.Y., Yang, H.S., 2018. Dietary composition and trophic niche partitioning of spotty-bellied greenlings Hexagrammos agrammus, fat greenlings $H$. otakii, Korean rockfish Sebastes schlegelii, and Japanese Seaperch Lateolabrax japonicus in the Yellow Sea revealed by stomach content analysis and stable isotope analysis. Mar. Coast. Fish 10 (2), 255-268. https://doi.org/10.1002/mcf2.10019.

Zhang, B., Li, Z.Y., Jin, X.S., 2014. Food composition and prey selectivity of Sebastes schlegeli. J. Fish. Sci. China 21 (1), 134-141. https://doi.org/10.3724/ SP.J.1118.2014.00134 (Chinese with English Abstract). 